\title{
Associations of mode and distance of commuting to school with cardiorespiratory fitness in Slovenian schoolchildren: a nationwide cross-sectional study
}

Gregor Jurak', Maroje Soric ${ }^{1,2}$, Vedrana Sember ${ }^{1}$, Sasa Djuric ${ }^{1 *}$ (D), Gregor Starc ${ }^{1}$, Marjeta Kovac ${ }^{1}$ and Bojan Leskosek'

\begin{abstract}
Background: It is unclear whether active commuting has the potential to improve children's health. This study examined the association of commuting mode and distance with children's cardiorespiratory fitness (CRF).

Methods: We conducted a cross-sectional study, including 713 Slovenian schoolchildren aged 12 to 15 years. Commuting modes were self-reported, and four commuting groups were constructed, while CRF was determined with a 20-m shuttle run test. The distance from home to school was calculated using the Geographic Information System. Effects of commuting mode and distance, controlling for age, gender and amount of total physical activity, were evaluated using general two linear models (one for each direction of commuting to/from school).

Results: The main effect of commuting group on CRF and its interaction with distance were significant in the direction from school to home ( $P=0.013$ and $P=0.028$, respectively), but not in the opposite direction. Predicted differences in CRF between commuting groups were moderate and generally higher in males than in females. When comparing commuting group median distance from home to school, males driven by car had around $4 \mathrm{ml} /$ min/kg lower predicted CRF than those who walked $(P=0.01)$ or used wheels commuting (e.g., bicycle, skateboard).

\footnotetext{
* Correspondence: sasa.djuric@fsp.uni-lj.si

${ }^{1}$ Faculty of Sport, University of Ljubljana, Gortanova ulica 22, SI-1000 Ljubljana, Slovenia

Full list of author information is available at the end of the article
}

C C The Author(s). 2021 Open Access This article is licensed under a Creative Commons Attribution 4.0 International License, which permits use, sharing, adaptation, distribution and reproduction in any medium or format, as long as you give appropriate credit to the original author(s) and the source, provide a link to the Creative Commons licence, and indicate if changes were made. The images or other third party material in this article are included in the article's Creative Commons licence, unless indicated otherwise in a credit line to the material. If material is not included in the article's Creative Commons licence and your intended use is not permitted by statutory regulation or exceeds the permitted use, you will need to obtain permission directly from the copyright holder. To view a copy of this licence, visit http://creativecommons.org/licenses/by/4.0/. The Creative Commons Public Domain Dedication waiver (http://creativecommons.org/publicdomain/zero/1.0/) applies to the data made available in this article, unless otherwise stated in a credit line to the data. 
(Continued from previous page)

Conclusions: The distance of commuting had a small effect on CRF, except in the Car group where children who live close to school had significantly lower CRF than those living further away. Children driven by car who live within wheels or walk distance from school should be targeted by interventions promoting active transport.

Keywords: Youth, Health, Transportation, Distance to school, Mode choice, Cycling, Walking, Physical activity

\section{Background}

In recent decades, the lifestyles of young people have changed drastically $[1,2]$. One of the most noticeable changes is the reduction of their physical activity (PA) [3]. Findings from different countries have shown that active commuting to school can contribute to the achievement of daily recommendations for PA [4-8] and therefore has meaningful health implications. Evidence from all over the world suggests that country characteristics determine the modes of commuting to school; however, some common features exist. Young people who walk or cycle to and from school have higher daily levels of PA than those who commute to school by car or public transport [9].

Moreover, cycling as a mode of commuting to school has been related with higher cardiorespiratory fitness (CRF) [6, 10-13], which is known to be an essential health marker in young people [14]. This association was found in both rural and urban children and adolescents from Denmark, United Kingdom, Estonia and Sweden [6, 10-13]. In addition, change in commuting mode from non-cycling to cycling was a significant predictor of CRF at follow-up in Danish children. Participants who changed to cycling at follow-up, had CRF significantly higher than those who did not cycle to school at either time point, with a difference of 9\% [12]. In another study from Denmark, cyclists had higher aerobic power (4.6-5.9\%), isometric muscle endurance (10-16\%), dynamic muscle endurance in the abdominal muscles (10\%) and flexibility (6\%) than both walkers and passive travelers [10]. However, when studying the effects of active commuting, the distance from home to school should be considered, as this variable can have a mediating and moderating effect. It is well-known that children who actively commute live closer to school $[5,15-18]$, but those who walk to school are more likely to live too close for a positive effect of their active commuting on their physical fitness to be exerted [19], since their walking distance is short and intensity is only low or moderate. In contrast, living too far from school may result in opting for non-active ways of commuting. What the acceptable distance for active commuting to school is depends on the environmental as well as individual and family characteristics $[15,20]$. The results of a British study showed that the threshold distance that best discriminated walkers from passive commuters in the 10-year-old schoolchildren from urban and rural areas was $1.4 \mathrm{~km} \mathrm{[21].} \mathrm{Another} \mathrm{study} \mathrm{showed} \mathrm{that} \mathrm{this} \mathrm{distance}$ in schoolchildren from urban areas of Belgium was $1.5 \mathrm{~km}$ [22], while findings from urban areas of Australia, Spain and USA suggest that children who live farther than around $800 \mathrm{~m}$ from their school are less likely to actively commute $[17,23,24]$.

The current study aimed to examine the effect of commuting mode and distance on children's CRF. A small number of studies have assessed these associations $[6,11,12,25]$, and this study is, to the best of our knowledge, among the first that accounted for distance to school when examining the relationship between commuting mode and CRF level. We hypothesize that children using physically active commuting will have higher CRF than children using passive modes of commuting, and that distance will have a positive effect on CRF among active commuters.

\section{Methods}

Study sample and design

In the study, we included participants in Grades 6, 7, 8, and 9 from the extensive research The Analysis of Children's Development in Slovenia (ACD.Si) [26]. In short, the sample was selected using a multistage, stratified sampling design. Ten research project sites were selected according to four types of Slovenian settlements (village, rural town, industrial town and city) and regions. Data collection took place in September and October 2013. The total sample size was 1124 (609 boys, 515 girls), while 713 schoolchildren (53.3\% male), age from 11.7 to 15.6 years $(M=13.3, S D=0.9)$, had valid data on commuting, home address, CRF and weekly PA, which was inclusion criteria in this study.

ACD.si is a multi-decennial, repeated cross-sectional study conducted in a representative sample of children, and powered to give precise prevalence estimates and detect secular trends in children's somatic and motor development. A post-hoc power analysis showed that, given the number of individuals included in this analysis $(N=713)$, number of predictors in the models $(N=6)$ and an alpha value set at 0.05 , we had sufficient power (beta $=0.81)$ to detect small effect size $(f=0.14)$.

The study was approved by the Commission of the Republic of Slovenia for Medical Ethics (No. 138/05/13). One parent or legal guardian provided written, informed consent to include his/her child in the study. The design 
and procedures of ACD. Si study have been described in more detail previously [26].

\section{Measurement of commuting to school}

To determine the mode of commuting from home to school, participants completed a computerized questionnaire, including the following question: "In what way did you usually commute to school in the last seven days? If you have used two or more commuting modes, choose the one for which you spent the most time." This was followed by an identical question for commuting from school to home. Similar questions were used before [27]. Possible answers were by car; by bus or train; walking; by bicycle; and by skateboard, roller skates, or kick scooter. Therefore, participants could select different commuting mode to school and from school. As just few participants commuted by skateboard, roller skates, or kick scooter, these modes were aggregated with bicycle, hence four commuting groups were formed for each direction: Car, Public, Wheels and Walk group (see the description of groups in Table 2).

\section{Evaluation of cardiorespiratory fitness}

CRF was determined using a 20-m shuttle run test [28]. The test has a moderate-to-high criterion validity for estimating the maximum oxygen uptake $\left(\mathrm{VO}_{2} \mathrm{max}\right.$; $r=0.66-0.84)$, which is higher when other variables (e.g. sex, age or body mass) are taken into account $(r=0.78-0.95)$ [29]. Moreover, it has a test-retest reliability coefficient of 0.89 for children [28]. To minimise measurement bias, the test was additionally monitored with heart rate monitors (Polar Accurex Plus and Polar S610i). The criteria for exhaustion was a heart rate of $\geq 185$ beats per min. CRF was expressed as $\mathrm{VO}_{2}$ max relative to body weight in $\mathrm{ml}$ of oxygen per $\mathrm{kg}$ of body mass per minute by using the quadratic formula from the Pacer Linear Model 2 protocol [30].

\section{Assessment of physical activity}

Physical activity/inactivity patterns were assessed using the School Health Action, Planning and Evaluation System (SHAPES) PA questionnaire [31]. We created a web-based questionnaire for our study; the layout of the questionnaire remained identical to the original paper version. Two items required a seven-day recall of vigorous PA and moderate PA. The SHAPES questionnaire has acceptable reliability (the overall kappa/weighted kappa coefficient for the test-retest reliability was 0.57 $+/-0.24$ ) and validity (Spearman $\mathrm{r}$ with accelerometermeasured average daily time spent performing MVPA = $0.44)$, and it is suitable for use in large-scale school-based data collections for child and adolescent populations [32]. For the purpose of the current study, PA was expressed as moderate-to-vigorous physical activity (MVPA) in min per week.

\section{Assessment of distance from home to school}

The distance in each direction (from home to school and vice versa) was determined by the home and school geographical coordinates and the actual (street) distance between them. We acquired the addresses from the parents, and then calculated actual distance using a web application Here.com. For all distances, the application considered the actual mode of transport, except for public transport, where actual distances were not known. Therefore, for this group we used the distance by car.

\section{Data analysis}

All statistical analyses were performed using the IBM SPSS Statistics 25 (IBM Corporation, Chicago, IL, USA). To evaluate the relationship between the commuting group and distance from school with CRF, controlling for gender, age and MVPA, the following linear models (one for each direction of commuting) were built: $\mathrm{VO}_{2}$ max' $=$ constant + commuting group + gender + MVPA + age + commuting group $\times$ gender + commuting group $x$ distance. As we expected the distance to have a different effect on CRF in different commuting groups, distance was included only in interaction with the commuting group, not as a main effect. Due to skewed distribution (and non-normal distribution of residuals as a consequence) square root transformation for MVPA and log (base 2) transformation for distance were performed before entering the model; before the transformation Pearson's moment coefficient of skewness $g_{3}$ was 0.71 and 3.61 , and after transformation it was -0.13 and -0.05 , for MVPA and distance, respectively. After the final models were constructed, commuting groups and gender adjusted marginal means with 95\% prediction intervals of CRF were calculated at commuting group median street distance from home to school and vice versa; median instead of usual mean was used due to right-skewed distribution of this variable and therefore mean would represent biased estimation of central tendency of the data; similarly, group instead of overall (grand) statistics was used due to enormous differences in commuting between different groups (e.g., car vs. walk group).

\section{Results}

Overall, $43 \%$ of the participants reported active commuting modes to and from school and an additional 13\% only in one direction (Table 1).

Participants more often used active commuting from school (56\%) than to school (44\%). Males and females were choosing active commuting equally often, though the notable difference was that females preferred to walk 
Table 1 Frequency of different modes of commuting to/from school

\begin{tabular}{|c|c|c|c|c|c|c|c|}
\hline & \multirow{2}{*}{$\begin{array}{l}\text { Commuting } \\
\text { modes }\end{array}$} & \multicolumn{6}{|c|}{ Commuting from school } \\
\hline & & $\overline{C a r}$ & Bus, train & Bicycle & $\begin{array}{l}\text { Skateboard, roller } \\
\text { skates, kick scooter }\end{array}$ & Walk & Total \\
\hline \multirow[t]{6}{*}{ Commuting to school } & Car & $58(8.1 \%)$ & $54(7.6 \%)$ & 0 & $1(0.1 \%)$ & $57(8.0 \%)$ & $170(23.8 \%)$ \\
\hline & Bus, train & $10(1.4 \%)$ & $190(26.6 \%)$ & 0 & 0 & $30(4.2 \%)$ & $230(32.3 \%)$ \\
\hline & Bicycle & 0 & 0 & $23(3.2 \%)$ & 0 & $7(1.0 \%)$ & $30(4.2 \%)$ \\
\hline & $\begin{array}{l}\text { Skateboard, roller } \\
\text { skate, kick scooter }\end{array}$ & 0 & 0 & 0 & $4(0.6 \%)$ & 0 & $4(0.6 \%)$ \\
\hline & Walk & $3(0.4 \%)$ & $1(0.1 \%)$ & 0 & 0 & $275(38.6 \%)$ & $279(39.1 \%)$ \\
\hline & Total & $71(10 \%)$ & $245(34.4 \%)$ & $23(3.2 \%)$ & $5(0.7 \%)$ & $369(51.8 \%)$ & $713(100 \%)$ \\
\hline
\end{tabular}

Data show number of participants (\% of total sample)

and males preferred to use wheels transport. The Walk group had the lowest and Public group had the highest median distance from home to school (Table 2).

Linear regression models (Table 3) was used to evaluate the effects of commuting group and distance on CRF, adjusted for gender, age, and MVPA. Two models were constructed for each direction, one from home to school and one from school to home.

When commuting from school to home, both the main effect of commuting group and its interaction with distance were significant $(P=0.013$ and $P=0.028$, respectively). Compared to the Walk group as a reference (and holding values of the other predictors in the model equal), the Car group had a significantly lower predicted value of CRF $(B=-15.14, P=0.012)$. Similarly, the Car group was the only one where distance of travel was related to CRF having significant difference to the reference (Walk) group; namely, the participants with larger car travel distance had higher predicted $\mathrm{VO}_{2} \max$ $(\mathrm{B}=1.25, P=0.007)$. Although overall interaction of commuting group with gender was not significant $(P=0.12)$, the largest sample difference between males and females was observed in the reference group (Walk), but it was only significant in the Car group $(\mathrm{B}=-2.63, P=0.048)$.

When commuting from home to school neither main effect of commuting group, nor it's interactions with gender and commuting distance were significant.
Commuting groups and gender adjusted marginal means with $95 \%$ prediction intervals of CRF were calculated at commuting group median street distance from home to school and vice versa.

In males, (Fig. 1, red symbols) the Car group deviated the most having the lowest predicted $\mathrm{VO}_{2} \max$, while the Wheels group had the highest predicted $\mathrm{VO}_{2} \max$, with the overall difference between participants in these two commuting groups reaching 4.3 and $5.1 \mathrm{ml} / \mathrm{min} / \mathrm{kg}$ (commuting to and from school, respectively). The predicted $\mathrm{VO}_{2}$ max in the Car group was also significantly lower than in the Walk group in both directions, while with in the Public group it differed only in the school to home direction.

In females, differences in CRF between commuting groups were in general smaller than in males with prediction intervals of all four groups overlapping for both directions of commuting. However, the Wheels group still showed the highest predicted values of CRF, although this difference did not reach statistical significance, due to a very low number of female participants choosing this mode of transport. In males, the differences in the CRF mean values of commuting groups, together with no overlap of their prediction intervals, showed that besides the Wheels group (for 2.0 and 3.1 $\mathrm{ml} / \mathrm{min} / \mathrm{kg}$ ), the Walk group (for 1.7 and $3.3 \mathrm{ml} / \mathrm{min} / \mathrm{kg}$ ) and the Public group (for 0.6 and $2.5 \mathrm{ml} / \mathrm{min} / \mathrm{kg}$ ) also

Table 2 Commuting groups, their size and distance from home to school and from school to home

\begin{tabular}{|c|c|c|c|c|c|}
\hline \multirow{2}{*}{$\begin{array}{l}\text { Commuting } \\
\text { group }\end{array}$} & \multirow[t]{2}{*}{ Description } & \multicolumn{2}{|c|}{ From home to school } & \multicolumn{2}{|c|}{ From school to home } \\
\hline & & $\mathrm{N}(\%)$ & Distance $(\mathrm{m})^{\mathrm{a}}$ & $\mathrm{N}(\%)$ & $\overline{\text { Distance }(\mathrm{m})^{\mathrm{a}}}$ \\
\hline Car & Car & $170(24 \%)$ & $3133(3973)$ & $71(10 \%)$ & $3615(3920)$ \\
\hline Public & Bus/train & $230(32 \%)$ & $4783(4350)$ & 245 (34\%) & $4996(4070)$ \\
\hline Wheels & $\begin{array}{l}\text { Bicycle, skateboard, roller } \\
\text { skate or kick scooter }\end{array}$ & $34(5 \%)$ & $1367(2271)$ & $28(4 \%)$ & $1444(2511)$ \\
\hline Walk & Walk & $279(39 \%)$ & 799 (796) & $369(52 \%)$ & $973(1046)$ \\
\hline Total & & $713(100 \%)$ & & $713(100 \%)$ & \\
\hline
\end{tabular}

${ }^{\mathrm{a}}$ Median (IQR) 
Table 3 Parameters (regression coefficients) of the linear model for prediction of $\mathrm{VO}_{2}$ max by group and distance

\begin{tabular}{|c|c|c|c|c|}
\hline \multirow[t]{3}{*}{ Variables } & \multicolumn{4}{|c|}{ Adjusted model } \\
\hline & \multicolumn{2}{|c|}{ From home to school } & \multicolumn{2}{|c|}{ From school to home } \\
\hline & Coefficient & $95 \% \mathrm{Cl}$ & Coefficient & $95 \% \mathrm{Cl}$ \\
\hline Constant & $36.42^{* * *}$ & $(28.17,44.67)$ & $36.63^{* * *}$ & $(29.11,44.15)$ \\
\hline \multicolumn{5}{|l|}{ Commuting group } \\
\hline Car & -6.49 & $(-15.91,2.93)$ & $-15.14^{* *}$ & $(-26.88,-3.39)$ \\
\hline Public & -0.08 & $(-9.06,8.90)$ & -3.19 & $(-11.27,4.88)$ \\
\hline Wheels & 3.00 & $(-16.24,22.25)$ & 15.66 & $(-4.09,35.41)$ \\
\hline \multicolumn{5}{|l|}{ Walk (ref) } \\
\hline \multicolumn{5}{|c|}{ Interaction Commuting group $\times$ Distance $^{a}$} \\
\hline Car $\times$ Distance & 0.58 & $(-0.04,1.20)$ & $1.25^{* *}$ & $(0.34,2.17)$ \\
\hline Public $\times$ Distance & 0.06 & $(-0.49,0.61)$ & 0.33 & $(-0.21,0.88)$ \\
\hline Wheels $\times$ Distance & -0.09 & $(-1.79,1.62)$ & -1.15 & $(-2.89,0.60)$ \\
\hline Walk $\times$ Distance & -0.02 & $(-0.62,0.58)$ & 0.03 & $(-0.42,0.48)$ \\
\hline \multicolumn{5}{|l|}{ Gender } \\
\hline Males & $7.97^{* * *}$ & $(6.75,9.19)$ & $7.58^{* * *}$ & $(6.52,8.63)$ \\
\hline \multicolumn{5}{|l|}{ Females (ref) } \\
\hline \multicolumn{5}{|c|}{ Interaction Commuting group $\times$ Gender } \\
\hline Car $\times$ Males & $-2.20^{*}$ & $(-4.16,-0.24)$ & $-2.63^{*}$ & $(-5.23,-0.03)$ \\
\hline Public $\times$ Males & $-2.00^{*}$ & $(-3.81,-0.20)$ & -1.35 & $(-2.99,0.30)$ \\
\hline Wheels $\times$ Males & -1.95 & $(-7.49,3.60)$ & -3.10 & $(-9.31,3.12)$ \\
\hline \multicolumn{5}{|l|}{ Walk $\times$ Males (ref) } \\
\hline \multicolumn{5}{|l|}{ Covariates } \\
\hline$M_{V P A}{ }^{b}$ & $0.076^{* * *}$ & $(0.03,0.12)$ & $0.073^{* * *}$ & $(0.032,0.12)$ \\
\hline Age & $0.43^{*}$ & $(0.00,0.85)$ & 0.40 & $(-0.02,0.82)$ \\
\hline
\end{tabular}

${ }^{\text {a }}$ Street distance log values, ${ }^{\mathrm{b}}$ Moderate-to-vigorous physical activity squared values

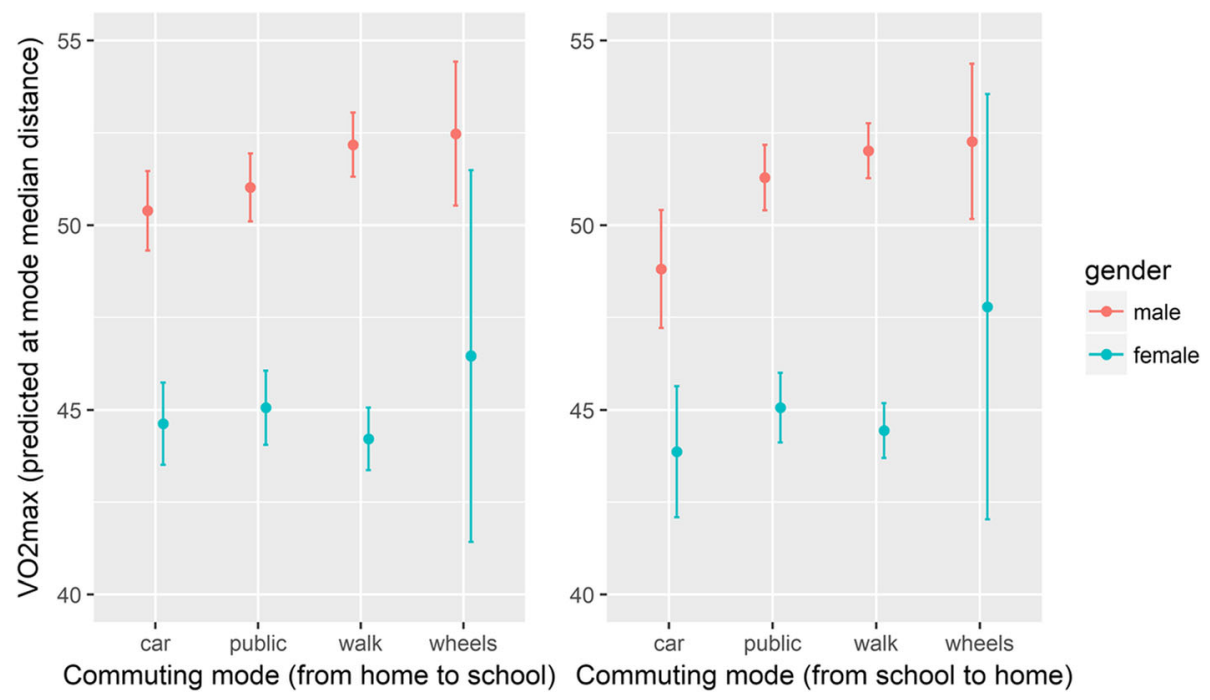

Fig. 1 Predicted values with 95\% confidence intervals of VO2max evaluated at commuting group median distances 
had significantly higher predicted CRF than the Car group did (commuting to and from school, respectively).

\section{Discussion}

This study investigated children's patterns of commuting to and from school and the association of commuting type and distance on children's CRF, controlling for gender, age and MVPA. The main finding of this study was that the distance of commuting had a small effect on CRF, except in the Car group, in which children who live close to school had significantly lower CRF than those living further away. Second important finding was that children driven from school by car had lower CRF compared to their peers who walked home from school or used wheels commuting (e.g., bicycle, skateboard). At the same time, this was not shown for commuting from home to school.

Overall differences in CRF between commuting groups and its interaction with distance to school and gender were noted only for commuting from school to home, but not from home to school. Similarly, the results of a study from Spain showed different modes of commuting to and from school. In particular, more children and adolescents commuted by walking and by public transport and less by car on their way from school compared to the way to school [33]. A similar trend was found in other studies from US [34-36], Iran [37] and Canada [38], indicating that 4, 6 and $8 \%$ more children and adolescents respectively walked from school than to school. This suggests that the non-active commuting to school in the morning is often linked to parental convenience of dropping a child at school on the way to work and not necessarily to the reservations towards active commuting or active lifestyle [39, 40]. Namely, for the age group included in this study school starts between 7.30 and 8.15 a.m., which corresponds to parents' departure to work. It is worth noting that, apart from commuting to school, later school start is associated with more sleep [41, 42], better academic performance [42] and decreased risk of motor vehicle crashes [41]. On the other hand, differences in CRF between commuting groups in the direction from school to home could be a result of various activities on the way home (going to playgrounds, playing with peers etc.). Observing only this direction of commuting, analysis showed that the Car group had a significantly lower predicted value of CRF compared to the Walk and the Wheels groups. This was confirmed by the evaluation of $\mathrm{VO}_{2} \mathrm{max}$ in the commuting groups' median distances from school to home, which detected differences of $10.48 \%$ in aerobic power between two extreme groups (the Car group and the Wheels group). Since more than three quarters of our participants in the Wheels group used bikes, this study adds to the scant evidence of specific benefit for schoolchildren of cycling to school. Several other studies also reported superior CRF in young people who cycle to school $[6,10-13]$. Cycling requires higher intensity of PA than other modes of commuting [43] the distances are usually longer than in walking [44], which was also confirmed in this study, and children who cycle travel faster and can spare more time to stop and play with friends before they return home than children who walk.

Predicted differences in CRF between commuting groups were moderate and generally higher in males than in females. Car driven males had around $4 \mathrm{ml} / \mathrm{min} /$ $\mathrm{kg}$ lower predicted CRF than those who walked or used wheels commuting. In general, the Car group had the lowest predicted CRF among all commuting types but the commuting distance had an inverse effect on CRF only in this group, where the car-driven children who lived close to school had significantly lower CRF than those living further away. Close proximity to school combined with commuting by car can therefore be considered an indicator of poor fitness. For the more distant Car group, we could conclude that these children have little choice and that such a commuting mode does not identify their overall lifestyle. Additionally, we may assume that they are well-supported by parents for organised sports activities, which influences their physical fitness. The results of the only prior study that had investigated the association of CRF with commuting mode while accounting for the distance in 10-year-olds, revealed that there were no significant differences in CRF between active and passive commuters to school [45]. Note that active commuters lived closer to school compared with passive commuters. In addition, the study found an inverse relationship between active commuting and CRF when deprivation was considered.

The differences in predicted CRF between boys who walked or cycled to and from school were almost nonexistent (see Fig. 1). This is somewhat surprising and is not in line with previous studies $[6,10,12,46]$. It may be at least partly attributable to short distances from school to home (median distances were 0.97 and 1.14 $\mathrm{km}$ in the Walk and the Wheels groups, respectively) and the similar (small) amount of PA, needed for commuting (alone) in those two groups. The other possible explanation of somewhat high CRF in the Walk and Wheels groups may be that during commuting from school to home these children might experience some spontaneous PA (e.g., running around or playing ball games at outdoor playgrounds that are easily accessible in Slovenia). This practice is probably more frequent in boys, which may explain the smaller difference between the Car and the Walk groups in girls than in boys. In support of this assumption is the fact that the greatest differences among The Car and Walk groups were observed when commuting from school to home, 
compared with commuting from home to school. This finding has not been identified in the existing studies and potentially indicates that spontaneous play and other physical activities on the way home could have impact on children's health (in our case more pronounced in boys).

Note that, commuting to school may represent a relatively small amount of total PA of Slovenian children compared to their all other daily physical activities, as the active commuting groups (Walk Wheels) typically live close to school (Table 2). In comparison with peers from other countries, they have a large number of physical education classes and free extra-curricular activities within school setting [47] and are among the most physically active children in the world [48, 49]. Hence, the CRF of our participants is very high compared to their peers worldwide. Namely, mean values of $\mathrm{VO}_{2} \max$ in this study correspond to the 90th and 80th percentiles of the international normative $20 \mathrm{~m}$ shuttle run values for boys, and girls, respectively [50].

Furthermore, our findings are determined by commuting patterns which depend on the personal and family factors, such as parental and child perception of distance and safety, school characteristics such as the school district and school legislation on daily school transport, and social and physical environmental factors such as the distance to the school, traffic safety and bike trails [15]. Therefore, the phenomenon of commuting to school is highly complex. Our results showed that $43 \%$ of children in our sample used active modes of commuting to and from school and walking was the most usual mode. Due to the lack of standardised protocols for identifying active versus non-active commuters, it is difficult to compare data from different studies [19]. Nevertheless, findings from the current study suggest that the prevalence of active commuting to school in Slovenia is similar to that in other European countries [11, 51-54], with the exception of countries with a strong tradition and infrastructure of bicycle transport (e.g., the Netherlands, Denmark). Regarding gender, the present study showed a somewhat different picture than in most previous studies that found active commuting to be more frequent in boys than in girls $[6,11,17,44,55]$. Specifically, we noticed a similar prevalence of active commuting to school in boys and in girls, yet there was a difference in active commuting modes by gender. More girls than boys walked to school, while more boys than girls used the so-called Wheels commuting to school. According to Slovenian school legislation, students (Grades 1-9) have the right to free transportation to school if their residence is more than four kilometers from the primary school. Therefore, the majority of schoolchildren who live that far from school used the Public commuting type, and some used the Car type. However, children living less than four kilometers from school commuted there using different modes. Although a more detailed analysis of determinants for modes choices of commuting is needed, the results of this study suggest that there is a meaningful proportion of children who use nonactive commuting to school for the wrong reasons. Specifically, $12 \%$ of participants in our study were driven to school by car, or they went to school with public transport in the morning but walked from school to home in the afternoon. This implies that they live within walking distance from school. In addition to the abovementioned benefits of later school start times for children, we could assume that more of them would use active commuting to school if this was the case.

Accordingly, the results from this study offer a powerful incentive to environments where rates of driven children who live within wheeling or walking range from school are high, to intervene for greater use of wheels and walk types of commuting. It is precisely with such active commuting to school that these children could increase their level of overall daily PA and, consequently, gain some health benefits [56]. For example, for children of this age group living within $2 \mathrm{~km}$ from school, selfpaced cycling (assuming a speed of $15 \mathrm{~km} / \mathrm{h}$ ) would result in 16 min of MVPA [57], representing around $12 \%$ of total daily MVPA in 11-year-old Slovenians [58, 59] and even $21 \%$ of daily MVPA in 14-year-old girls [60]. In addition to having a direct impact on increasing the overall PA of the child, this practice could have another crucial indirect influence. Specifically, the findings suggest that, among others, high autonomy and good weather are important factors for choosing active commuting over other transport forms for traveling short distances [61, 62]. Car-driven children are getting less opportunities for mastering their built environment (e.g., crossing roads) and adapting to be physically active in different weather conditions (e.g., walking in the rain) and therefore gain less competences for active transport in their free time than their actively-commuting peers. Additionally, driving children from school on relatively short distance could also indicate an inappropriate parental attitude towards active commuting due to their over-protective behavior. This can affect children's overall PA level, as indicated by a prior study that used accelerometers to compare children' daily PA patterns based on the mode of travel to school [4].

\section{Strengths and limitations of the study}

The strengths of this study include a consistent and accurate measurement protocol, a relatively large sample size, information on a different modes of commuting to and from school, the use of a reliable field-based measurement of CRF [28] and consideration of the actual commuting distance between home and school when 
examining the association between the type of commuting and CRF. However, there are several limitations as well. First, the cross-sectional design precludes making inference on the causality in the relationship between commuting mode and CRF. Second, the subjective method (questionnaire) and type of questions used for obtaining information on the mode of commuting (recall for past 7 days) may not reflect the usual commuting modes. Third, a small number of participants who used Wheels type of commuting, resulted in loss of precision of the estimates for this mode of transport. Finally, the differences in CRF could be driven by other forms of physical activity as in Slovenia commuting to and from school represents only a small fraction of total daily PA; hence, we may expect that differences between commuting types are (even) higher in most of the other populations. Fourth, the variability of results may also be influenced by other factors (e.g. socioeconomic status, education etc.) which, however, have not been studied due to the complexity of the set model.

\section{Conclusion}

This study demonstrated that active commuting to and from school is associated with higher CRF levels in actively-commuting children when compared to their peers who commute by car, especially when commuting from school to home. Possible health benefits for children who use Wheels kinds of commuting (by bicycle, skateboard, roller-skate or kick scooter) and walking illustrate the need for increasing the efforts to promote active commuting. Furthermore, parents who drive their children to school either in one or both directions while living in a walking or cycling range seem to be the most promising target group for active commuting interventions. To this end, schools and local communities should be encouraged to provide infrastructure support, such as safe routes to schools, slower traffic in the school district, and bicycle or other wheeled equipment storage at school.

\section{Acknowledgments}

The authors acknowledge the support of the schools from the ACDSi study and the help of the participants that took part in the study and thank their parents for their collaboration.

\section{Authors' contributions}

GJ conceptualized work and was a major contributor in writing the paper. MS interpreted data and revised drafted paper. VS contributed to design, acquisition of data, writing and editing of paper. SD contributed to writing and editing of paper. GS contributed to conceptualization, data acquisition, interpretation, writing and revising of paper. MK contributed to design of the study and interpretation of data. BL analysed and interpreted the data, prepared visualization and contribute to writing, reviewing and editing of paper. All authors read and approved the final manuscript.

\section{Funding}

The authors acknowledge the ACDSi study was financially supported by the Slovenian Research Agency within the programme Bio-Psycho-Social Context of Kinesiology (ID P5-0142).

\section{Availability of data and materials}

The datasets used and/or analysed during the current study are available from the corresponding author on reasonable request.

Ethics approval and consent to participate

The study was approved by the Commission of the Republic of Slovenia for Medical Ethics (No. 138/05/13). One parent or legal guardian provided written, informed consent to include his/her child in the study.

\section{Consent for publication}

Not applicable.

\section{Competing interests}

The authors declare that they have no competing interests.

\section{Author details}

${ }^{1}$ Faculty of Sport, University of Ljubljana, Gortanova ulica 22, SI-1000 Ljubljana, Slovenia. ${ }^{2}$ Faculty of Kinesiology, University of Zagreb, Horvacanski zavoj 15, 10110 Zagreb, Croatia.

Received: 4 June 2020 Accepted: 25 January 2021

Published online: 04 February 2021

\section{References}

1. Pate RR, Mitchell JA, Byun W, Dowda M. Sedentary behaviour in youth. Br J Sports Med. 2011:45(11):906-13.

2. Sedlak P, Pařízová J, Daniš R, Dvoráková H, Vignerová J. Secular changes of adiposity and motor development in Czech preschool children: lifestyle changes in fifty-five year retrospective study. Biomed Res Int. 2015;2015:1-9.

3. Ekelund $\mathrm{U}$, Tomkinson $\mathrm{G}$, Armstrong N. What proportion of youth are physically active? Measurement issues, levels and recent time trends. Br J Sports Med. 2011;45(11):859-65.

4. Cooper AR, Andersen LB, Wedderkopp N, Page AS, Froberg K. Physical activity levels of children who walk, cycle, or are driven to school. Am J Prev Med. 2005;29(3):179-84.

5. Cooper AR, Page AS, Foster LJ, Qahwaji D. Commuting to school: are children who walk more physically active? Am J Prev Med. 2003;25(4):273-6.

6. Cooper AR, Wedderkopp N, Wang HAN, Andersen LB, Froberg K, Page AS. Active travel to school and cardiovascular fitness in Danish children and adolescents. Med Sci Sports Exerc. 2006;38(10):1724-31.

7. Rosenberg DE, Sallis JF, Conway TL, Cain KL, McKenzie TL. Active transportation to school over 2 years in relation to weight status and physical activity. Obesity. 2006;14(10):1771-6.

8. Sirard JR, Riner JWF, Mclver KL, Pate RR. Physical activity and active commuting to elementary school. Med Sci Sports Exerc. 2005;37(12):2062-9.

9. Larouche R, Saunders TJ, John Faulkner GE, Colley R, Tremblay M. Associations between active school transport and physical activity, body composition, and cardiovascular fitness: a systematic review of 68 studies. J Phys Act Health. 2014;1 1(1):206-27.

10. Andersen LB, Lawlor DA, Cooper AR, Froberg K, Anderssen SA. Physical fitness in relation to transport to school in adolescents: the Danish youth and sports study. Scand J Med Sci Sports. 2009;19(3):406-11.

11. Chillón P, Ortega FB, Ruiz JR, Veidebaum T, Oja L, Mäestu J, et al. Active commuting to school in children and adolescents: an opportunity to increase physical activity and fitness. Scand J Public Health. 2010;38(8):873-9.

12. Cooper AR, Wedderkopp N, Jago R, Kristensen PL, Moller NC, Froberg K, et al. Longitudinal associations of cycling to school with adolescent fitness. Prev Med (Baltim). 2008;47(3):324-8.

13. Voss C, Sandercock G. Aerobic fitness and mode of travel to school in English schoolchildren. Med Sci Sports Exerc. 2010;42(2):281-7.

14. Ortega FB, Ruiz JR, Castillo MJ, Sjöström M. Physical fitness in childhood and adolescence: a powerful marker of health. Int J Obes. 2008;32(1):1.

15. Davison KK, Werder JL, Lawson CT. Peer reviewed: children's active commuting to school: current knowledge and future directions. Prev Chronic Dis. 2008;5(3):A100.

16. McDonald NC. Children's mode choice for the school trip: the role of distance and school location in walking to school. Transportation (Amst). 2008;35(1):23-35. 
17. Timperio A, Ball K, Salmon J, Roberts R, Giles-Corti B, Simmons D, et al. Personal, family, social, and environmental correlates of active commuting to school. Am J Prev Med. 2006;30(1):45-51.

18. Metcalf $B$, Voss $L$, Jeffery A, Perkins J, Wilkin T. Physical activity cost of the school run: impact on schoolchildren of being driven to school (EarlyBird 22). BMJ. 2004:329(7470):832-3.

19. Faulkner GEJ, Buliung RN, Flora PK, Fusco C. Active school transport, physical activity levels and body weight of children and youth: a systematic review. Prev Med (Baltim). 2009;48(1):3-8.

20. Ikeda E, Hinckson E, Witten K, Smith M. Assessment of direct and indirect associations between children active school travel and environmental, household and child factors using structural equation modelling. Int J Behav Nutr Phys Act. 2019;16(1):32.

21. Chillón P, Panter J, Corder K, Jones AP, Van Sluijs EMF. A longitudinal study of the distance that young people walk to school. Health Place. 2015;31:133-7

22. D'Haese S, De Meester F, De Bourdeaudhuij I, Deforche B, Cardon G. Criterion distances and environmental correlates of active commuting to school in children. Int J Behav Nutr Phys Act. 2011;8(1):88.

23. Rodríguez-López C, Salas-Fariña ZM, Villa-González E, Borges-Cosic M, Herrador-Colmenero M, Medina-Casaubón J, et al. The threshold distance associated with walking from home to school. Health Educ Behav. 2017; 44(6):857-66.

24. McMillan TE. The relative influence of urban form on a child's travel mode to school. Transp Res Part A Policy Pract. 2007;41(1):69-79.

25. Gutiérrez-Zornoza M, Sánchez-López M, García-Hermoso A, González-García A, Chillón P, Martínez-Vizcaíno V. Active commuting to school, weight status, and cardiometabolic risk in children from rural areas: the Cuenca study. Health Educ Behav. 2015;42(2):231-9.

26. Jurak G, Kovač M, Starc G. The ACDSi 2013 - the analysis of children's development in Slovenia 2013: study protocol. Anthropol Notebooks. 2013; 19(3):123-43.

27. Robertson-Wilson JE, Leatherdale ST, Wong SL. Social-ecological correlates of active commuting to school among high school students. J Adolesc Health. 2008;42(5):486-95.

28. Leger LA, Mercier D, Gadoury C, Lambert J. The multistage 20 metre shuttle run test for aerobic fitness. J Sports Sci. 1988;6(2):93-101.

29. Mayorga-Vega D, Aguilar-Soto P, Viciana J. Criterion-related validity of the 20-m shuttle run test for estimating cardiorespiratory fitness: a metaanalysis. J Sports Sci Med. 2015;14(3):536.

30. Mahar MT, Guerieri AM, Hanna MS, Kemble CD. Estimation of aerobic fitness from 20-m multistage shuttle run test performance. Am J Prev Med. 2011; 41(4):S117-23.

31. Leatherdale ST, Manske S, Wong SL, Cameron R. Integrating research, policy, and practice in school-based physical activity prevention programming: the School Health Action, Planning, and Evaluation System (SHAPES) physical activity module. Health Promot Pract. 2009:10(2):254-61.

32. Wong SL, Leatherdale ST, Manske SR. Reliability and validity of a school-based physical activity questionnaire. Med Sci Sports Exerc. 2006; 38(9):1593-600.

33. Herrador-Colmenero M, Escabias M, Ortega FB, McDonald NC, Chillón P. Mode of commuting TO and FROM school: a similar or different pattern? Sustainability. 2019;11(4):1026.

34. Seraj S, Sidharthan R, Bhat CR, Pendyala RM, Goulias KG. Parental attitudes toward children walking and bicycling to school: multivariate ordered response analysis. Transp Res Rec. 2012;2323(1):46-55.

35. Zhu X, Lee C. Correlates of walking to school and implications for public policies: survey results from parents of elementary school children in Austin, Texas. J Public Health Policy. 2009;30(1):S177-202.

36. McDonald NC, Steiner RL, Lee C, Rhoulac Smith T, Zhu X, Yang Y. Impact of the safe routes to school program on walking and bicycling. J Am Plan Assoc. 2014;80(2):153-67.

37. Samimi A, Ermagun A. Students' tendency to walk to school: case study of Tehran. J Urban Plan Dev. 2013:139(2):144-52.

38. Larsen K, Gilliland J, Hess PM. Route-based analysis to capture the environmental influences on a child's mode of travel between home and school. Ann Assoc Am Geogr. 2012;102(6):1348-65.

39. Panter J, Corder K, Griffin SJ, Jones AP, van Sluijs EMF. Individual, sociocultural and environmental predictors of uptake and maintenance of active commuting in children: longitudinal results from the SPEEDY study. Int J Behav Nutr Phys Act. 2013;10(1):83.
40. McDonald NC, Aalborg AE. Why parents drive children to school: implications for safe routes to school programs. J Am Plan Assoc. 2009. 75(3):331-42.

41. Danner F, Phillips B. Adolescent sleep, school start times, and teen motor vehicle crashes. J Clin Sleep Med. 2008;4(6):533-5.

42. Dunster GP, de la Iglesia L, Ben-Hamo M, Nave C, Fleischer JG, Panda S, et al. Sleepmore in Seattle: later school start times are associated with more sleep and better performance in high school students. Sci Adv. 2018;4(12): eaau6200.

43. Hendriksen IJM, Zuiderveld BOB, Kemper HCG, Bezemer PD. Effect of commuter cycling on physical performance of male and female employees. Med Sci Sports Exerc. 2000;32(2):504.

44. Nelson NM, Foley E, O'gorman DJ, Moyna NM, Woods CB. Active commuting to school: how far is too far? Int J Behav Nutr Phys Act. 2008;5(1):1.

45. Noonan RJ, Boddy LM, Knowles ZR, Fairclough SJ. Fitness, fatness and active school commuting among Liverpool schoolchildren. Int J Environ Res Public Health. 2017;14(9):995

46. Østergaard L, Kolle E, Steene-Johannessen J, Anderssen SA, Andersen LB. Cross sectional analysis of the association between mode of school transportation and physical fitness in children and adolescents. Int I Behav Nutr Phys Act. 2013;10(1):91.

47. Kerpanova $\mathrm{V}$, Borodankova O. Physical education and sport at school in Europe. Brussels: ERIC; 2013.

48. Aubert S, Barnes JD, Abdeta C, Abi Nader P, Adeniyi AF, Aguilar-Farias N, et al. Global matrix 3.0 physical activity report card grades for children and youth: results and analysis from 49 countries. J Phys Act Health. 2018; 15(Supplement 2):S251-73.

49. Sember V, Starc G, Jurak G, Golobič M, Kovač $M$, Samardžija PP, et al. Results from the Republic of Slovenia's 2016 report card on physical activity for children and youth. J Phys Act Health. 2016;13(11 Suppl 2): S256-64.

50. Tomkinson GR, Lang JJ, Tremblay MS, Dale M, LeBlanc AG, Belanger K, et al. International normative $20 \mathrm{~m}$ shuttle run values from 1142026 children and youth representing 50 countries. Br J Sport Med. 2017; 51(21):1545-54

51. Chillón P, Ortega FB, Ruiz JR, Pérez IJ, Martín-Matillas M, Valtueña J, et al. Socio-economic factors and active commuting to school in urban Spanish adolescents: the AVENA study. Eur J Public Health. 2009;19(5):470-6.

52. Bringolf-Isler B, Grize L, Mäder U, Ruch N, Sennhauser FH, Braun-Fahrländer C. Personal and environmental factors associated with active commuting to school in Switzerland. Prev Med (Baltim). 2008;46(1):67-73.

53. Panter JR, Jones AP, Van Sluijs EMF, Griffin SJ. Attitudes, social support and environmental perceptions as predictors of active commuting behaviour in school children. J Epidemiol Community Health. 2010; 64(01):41-8.

54. Martínez-Gómez D, Veiga OL, Gomez-Martinez S, Zapatera B, Calle ME, Marcos A. Behavioural correlates of active commuting to school in Spanish adolescents: the AFINOS (physical activity as a preventive measure against overweight, obesity, infections, allergies, and cardiovascular disease risk factors in adolescents) study. Public Health Nutr. 2011:14(10):1779-86.

55. Williams GC, Borghese MM, Janssen I. Objectively measured active transportation to school and other destinations among 10-13 year olds. Int J Behav Nutr Phys Act. 2018;15(1):11.

56. Martínez-Gómez D, Ruiz JR, Gómez-Martínez S, Chillón P, Rey-López JP, Díaz LE, et al. Active commuting to school and cognitive performance in adolescents: the AVENA study. Arch Pediatr Adolesc Med. 2011. 165(4):300-5.

57. Butte NF, Watson KB, Ridley K, Zakeri IF, McMurray RG, Pfeiffer KA, et al. A youth compendium of physical activities: activity codes and metabolic intensities. Med Sci Sports Exerc. 2018;50(2):246.

58. Jurak G, Sorić M, Starc G, Kovač M, Mišigoj-Duraković M, Borer K, et al. School day and weekend patterns of physical activity in urban 11-year-olds: a cross-cultural comparison. Am J Hum Biol. 2015;27(2):192-200.

59. Sember V, Morrison SA, Jurak G, Kovac M, Starc G. Differences in physical activity and academic performance between urban and rural schoolchildren in Slovenia. Montenegrin J Sport Sci Med. 2018;7(1):67-72.

60. Sember $V$. Impact of physical activity and physical fitness on academic performance in selected Slovenian schoolchildren: doctoral thesis: Univerza 
na Primorskem, Fakulteta za matematiko, naravoslovje in informacijske tehnologije. Koper: 2017.

61. Müller S, Tscharaktschiew S, Haase K. Travel-to-school mode choice modelling and patterns of school choice in urban areas. J Transp Geogr. 2008;16(5):342-57.

62. Simons D, Clarys P, De Bourdeaudhuij I, de Geus B, Vandelanotte C,

Deforche B. Factors influencing mode of transport in older adolescents: a qualitative study. BMC Public Health. 2013;13(1):323.

\section{Publisher's Note}

Springer Nature remains neutral with regard to jurisdictional claims in published maps and institutional affiliations.

Ready to submit your research? Choose BMC and benefit from:

- fast, convenient online submission

- thorough peer review by experienced researchers in your field

- rapid publication on acceptance

- support for research data, including large and complex data types

- gold Open Access which fosters wider collaboration and increased citations

- maximum visibility for your research: over $100 \mathrm{M}$ website views per year

At BMC, research is always in progress.

Learn more biomedcentral.com/submissions 